\title{
Libertad de expresión versus honra y buen nombre: colisiones entre principios y relaciones de precedencia en la jurisprudencia constitucional colombiana
}

\author{
Recibido: 5 de agosto de 2020 - Aprobado: 10 de septiembre de 2020 \\ https://doi.org/10.22395/ojum.v20n42a15
}

\author{
Pedro José Palacio Pardo \\ Universidad del Magdalena, Santa Marta, Colombia \\ palaciopedro08@gmail.com \\ https://orcid.org/0000-0003-4488-7507
}

\section{RESUMEN}

En este documento se muestran las relaciones de precedencia condicionadas identificadas en la jurisprudencia constitucional cuando se presentan colisiones entre los derechos fundamentales libertad de expresión, honra y buen nombre por posibles afectaciones derivadas del ejercicio periodístico. Al analizar estos casos concretos, resulta evidente que para el juzgador, plantear una solución lo menos lesiva posible representa un reto, porque se sitúa en un escenario en donde colisionan derechos jerárquicamente equiparables. Por tal razón, quien juzga debe acudir a la ponderación para determinar cuál principio precederá al otro. Así mismo, se tiene que a pesar del surgimiento reiterado de colisiones entre los derechos que son objeto de estudio, no se puede brindar una solución igualitaria para todas, puesto que los efectos de la ponderación son aplicables a casos concretos. No obstante, a partir de un seguimiento lineal de la jurisprudencia constitucional se ha podido concluir que el mayor o menor grado de veracidad e imparcialidad de la información es un factor determinante para que la balanza se incline hacia un lado u otro.

Palabras clave: derechos fundamentales; principios; ponderación; democracia y dignidad humana. 


\title{
Freedom of Speech versus Honor and Good Name: Collisions between Principles and Precedence Relations in the Colombian Constitutional Jurisprudence
}

\begin{abstract}
This document shows the conditioned precedence relations identified in the constitutional jurisprudence in cases of collisions between the fundamental rights of freedom of speech, honor, and good name derived from the journalistic practice. After analyzing these concrete cases, it is evident that proposing a lesser harmful solution is a challenge for the judging part because there is a scenario in which hierarchically comparable rights collide. For that reason, the judging part must weigh which principle will precede the other one. Likewise, despite the reiterated collision among the rights studied here, there cannot be an egalitarian solution for all of them, given that the effects of the weighing apply to concrete cases. Nonetheless, based on a linear follow-up of the constitutional jurisprudence, the study concludes that a higher or lower grade of veracity and impartiality of the information is a determining factor for inclining the balance towards one place or the other.
\end{abstract}

Keywords: fundamental rights; principles; weighing; democracy and human dignity. 


\section{INTRODUCCIÓN}

Existen situaciones que generan tensión entre los derechos que gozan de igual jerarquía constitucional, lo que termina desencadenando colisiones de derechos o principios fundamentales que deben ser resueltas por los operadores judiciales a través de la ponderación. En ese sentido, ha sido bastante fructífero el trabajo que ha desarrollado la Corte Constitucional en lo que respecta a la resolución de las confrontaciones entre los derechos fundamentes libertad de expresión, honra y buen nombre, toda vez que en su jurisprudencia ha creado relaciones de precedencia condicionada en casos concretos que permiten la prevalencia de alguno de estos principios sin necesidad de optar por el detrimento injustificado del principio opuesto.

Este escrito académico surge del interés del autor por investigar las colisiones entre los derechos objeto de estudio resultantes del ejercicio de la actividad periodística, razón por la cual se busca plantear reflexiones que contribuyan a la promoción del respeto por la libertad de expresión y del entendimiento colectivo de lo perjudicial que resulta la utilización de su carácter prevalente prima facie para justificar los ataques groseros a la honra y al buen nombre de las personas.

Así las cosas, es necesario tener en cuenta que el ejercicio del periodismo es la condición indispensable para la materialización de la libertad de expresión en su manifestación de libertad de información y de prensa, lo que a su vez genera un impacto significativo en el mantenimiento de una sociedad democrática. Por lo tanto, en este trabajo se abordarán casos emblemáticos en los cuales mediante la acción de tutela se busca el amparo de los derechos fundamentales a la honra y al buen nombre por posibles afectaciones derivadas del ejercicio periodístico. También, y se analizará la complejidad de estas situaciones, teniendo en cuenta que afloran cuestionamientos sobre el valor de cada principio constitucional y la manera en que deben ser tratados, ya que no se puede permitir la distorsión de la tutela a tal punto de convertirla en un instrumento de censura, así como tampoco resulta viable denegar su utilización para aquellos casos en donde la presunta vulneración a la honra o al buen nombre proviene de la actividad del periodista.

Investigar este asunto tiene como propósito primordial mostrar las relaciones de precedencia condicionadas identificadas en la jurisprudencia más destacada de la Corte Constitucional al momento de analizar casos relativos a las colisiones entre los derechos fundamentales libertad de expresión, honra y buen nombre. Todo esto de acuerdo con la metodología de la ponderación planteada por Robert Alexy (1993), cuestión que a su vez permite un acercamiento a la justicia y a la manera en que se abordan estas confrontaciones entre derechos equiparables en cuanto a su jerarquía constitucional. 
Las revisiones bibliográficas, jurisprudenciales, normativas y la formulación de líneas jurisprudenciales basadas en la estrategia de Diego López Medina (2006), han sido las herramientas metodológicas empleadas para el desarrollo de esta investigación y la correspondiente obtención de los resultados y conclusiones que se plantean. Dicho lo anterior, a continuación, se explicarán algunos elementos conceptuales y teóricos necesarios desde la óptica del derecho internacional de los derechos humanos, del derecho constitucional colombiano y de la doctrina planteada por los estudiosos de la ponderación, para luego hacer un recorrido por la jurisprudencia constitucional y culminar con el planteamiento de unas consideraciones finales.

\section{LIBERTAD DE EXPRESIÓN, HONRA Y REPUTACIÓN EN EL DERECHO INTERNACIONAL DE LOS DERECHOS HUMANOS}

Al abordar el estudio de las colisiones entre los derechos que tienen el distintivo de ser derechos humanos y al atender las particularidades del derecho constitucional colombiano, que indudablemente se encuentra permeado por el derecho internacional de los derechos humanos, resulta imperioso transitar por los diversos instrumentos internacionales de orden global y regional que consagran los derechos a la libertad de expresión, a la honra y a la reputación (buen nombre), donde al primero de estos se le otorga la categoría de elemento fundamental para el mantenimiento de la democracia, y se asocia a los otros dos con la dignidad humana. Las normas internacionales que se refieren a estos derechos siempre lo hacen mostrando una especie de sentido preventivo, de ahí que resulte curioso cómo incluso desde la propia redacción de los artículos se intentan plasmar límites para evitar, en mayor medida, la afectación de uno por la aplicación desproporcionada y favorita del otro.

\subsection{Libertad de expresión, honra y reputación en el sistema universal de protección de derechos humanos}

La Declaración Universal de los Derechos Humanos (DUDH) está dentro de esos instrumentos del Sistema Universal de Protección de Derechos Humanos que tocan el tema relativo a la libertad de expresión, encontrando sustento en su artículo 19, el cual hace alusión a la posibilidad que tiene toda persona de expresarse y opinar libremente sin ser molestado por esta razón y de poder difundir sus mensajes por el medio que considere más expedito (Naciones Unidas, 1948).

Como si se tuviera la intención de hacer uso tácito de aquella popular frase según la cual los derechos de los demás empiezan en donde terminan los míos, la DUDH también se refiere a la honra y a la reputación en los siguientes términos: "nadie será objeto de injerencias arbitrarias en su vida privada, su familia, su domicilio o su correspondencia, ni de ataques a su honra o a su reputación" (Naciones Unidas, 1948, art.12). 
Por otro lado, el artículo 19 del Pacto Internacional de Derechos Civiles y Políticos (PIDCP) también apunta en una dirección ampliamente proteccionista del derecho a la libertad de expresión. A su tenor se lee lo siguiente:

Toda persona tiene derecho a la libertad de expresión; este derecho comprende la libertad de buscar, recibir y difundir informaciones e ideas de toda índole, sin consideración de fronteras, ya sea oralmente, por escrito o en forma impresa o artística, o por cualquier otro procedimiento de su elección. (Naciones Unidad, 1966, art. 19)

No obstante, el instrumento también contiene una apreciación hacia los límites de este derecho, ya que no lo concibe como algo absoluto, sino que encuentra un freno en su ejercicio cuando con él se llegan a comprometer negativamente otros derechos, como el buen nombre de los demás o la seguridad y el orden público (Naciones Unidas, 1966). Esto implica que deba ser interpretado en armonía con lo dispuesto en el artículo 17, relativo al derecho a la honra, el cual dispone que "nadie será objeto de injerencias arbitrarias en su vida privada, su familia, su domicilio o su correspondencia, ni de ataques ilegales a su honra y reputación" (Naciones Unidas, 1966, art. 17). En este sentido, su materialización entraña la conocida relación entre derechos y deberes que, en este caso en particular, se refiere al deber de respeto hacia los demás y al orden constitucional y legal de cada Estado.

Además de las disposiciones mencionadas previamente, existen otros instrumentos que consagran estos derechos y sus limitantes. De esta manera, a título enunciativo se trae a colación la Convención sobre Derechos del Niño (1989) (artículos 13 y 16), la Convención Internacional sobre la Protección de los Derechos de todos los Trabajadores Migratorios y de sus Familiares (1990) (artículos 13 y 14), y la Convención Internacional sobre los Derechos de las Personas con Discapacidad (2006) (artículos 21 y 22).

\subsection{Libertad de expresión, honra y reputación en el sistema interamericano de protección de derechos humanos}

Desde el sistema regional de protección de derechos humanos también se observa la protección de los derechos que son objeto de estudio en este artículo y el establecimiento de límites en el ejercicio de estos. Así, por ejemplo, la Declaración Americana de los Derechos y Deberes del Hombre en su artículo 4 consagra el derecho que tiene toda persona de opinar, investigar, expresarse y difundir información sin mayores limitaciones (OEA, 1948). Seguidamente, el artículo 5 del mismo documento hace referencia al derecho a la honra y a la reputación, al establecer que las personas deben estar protegidas por la ley cuando se presenten ataques a estos derechos (OEA, 1948). Aquí se pone en evidencia, una vez más, la entrañable relación entre todas estas garantías y la necesidad de marcar pautas de respecto entre ellas. 
De acuerdo con Nikken (s.f.), la importancia de la enunciación de estos derechos en la Declaración Americana de los Derechos y Deberes del Hombre, radica en que al ser este un instrumento solemne, que en principio no tiene el carácter vinculante de un tratado, pone de manifiesto la intención de los Estados de reconocer ciertos derechos que terminan siendo principios fundamentales del derecho internacional. Por lo tanto, se convierten en normas perdurables, que incluso ayudan en la conformación de una costumbre internacional.

Por otro lado, el instrumento insignia del Sistema Interamericano de Protección de Derechos Humanos, es decir, la Convención Americana sobre Derechos Humanos, en su artículo 11 se refiere al derecho a la honra, aduciendo que "toda persona tiene derecho al respeto de su honra y al reconocimiento de su dignidad" (OEA, 1969, art. 11). En este sentido, establece la prohibición de injerencias arbitrarias en la vida privada de las personas y de los ataques a la reputación (OEA, 1969).

En lo atinente al derecho a la libertad de expresión, la CADH se encargó de hacer una descripción minuciosa de todos los elementos que lo comprenden. Por esto, el artículo 13 establece que toda persona tiene la libertad de pensar y expresar sus ideas, derecho que a su vez implica la posibilidad de buscar información, recibirla y difundirla sin limitaciones a través de medios escritos, orales o artísticos (OEA, 1969).

Asimismo, el numeral 3 del artículo 13 de la CADH contempla que no puede haber restricciones indirectas al derecho de expresión, y trae como ejemplos los siguientes tipos de limitaciones:

El abuso en los controles oficiales o particulares de papel para periódicos, de frecuencias radioeléctricas, o de enseres y aparatos usados en la difusión de información o por cualesquiera otros medios encaminados a impedir la comunicación y la circulación de ideas y opiniones. (OEA, 1969, art. 13)

Pese a lo anterior, la libertad de expresión también encuentra un límite cuando con ella se pretende hacer propaganda a la guerra, al odio y a la discriminación, de acuerdo con lo previsto en el numeral 5 del artículo 13 de la CADH (1969). De igual forma, es permitida la censura previa por la ley de los espectáculos públicos cuando se pretende la protección de la moral de los infantes y de los adolescentes, de acuerdo con lo establecido en el numeral 4 del mismo artículo (OEA, 1969). Sin embargo, el uso de las limitaciones a la libertad de expresión no es una potestad discrecional de los Estados, sino que para ello se deben seguir los planteamientos de la jurisprudencia de la Corte Interamericana de Derechos Humanos sobre la interpretación del artículo 13 de la CADH. En este sentido, el órgano colegiado ha establecido el llamado test tripartito para determinar la admisibilidad o no de una restricción al derecho a la libertad de expresión, el cual se compone de los siguientes aspectos: 
(1) la limitación debe haber sido definida en forma precisa y clara a través de una ley formal y material, (2) la limitación debe estar orientada al logro de objetivos imperiosos autorizados por la Convención Americana, y (3) la limitación debe ser necesaria en una sociedad democrática para el logro de los fines imperiosos que se buscan; estrictamente proporcionada a la finalidad perseguida; e idónea para lograr el objetivo imperioso que pretende lograr. (CIDH, 2009, p. 2)

La libertad de expresión también ha sido considerada el eje central de los Estados democráticos, puesto que entraña la posibilidad de que los ciudadanos se muestren críticos frente a la gestión de los dirigentes que asumen su papel como resultado de la confianza que los votantes depositan en ellos, lo que hace realizable una verdadera democracia. Este postulado se reafirma si se tiene en cuenta lo planteado en artículo 4 de la Carta Democrática Interamericana (2001), el cual contempla como componente fundamental de la democracia, entre otros aspectos, el derecho a la libertad de expresión y de prensa (OEA, 2001). Lo anterior, también se predica de lo establecido en la Declaración de Principios sobre Libertad de Expresión (DPLE), donde se dispone que "la libertad de expresión, en todas sus formas y manifestaciones, es un derecho fundamental e inalienable, inherente a todas las personas. Es, además, un requisito indispensable para la existencia misma de una sociedad democrática" (OEA, 2000, ppio. 1).

\subsubsection{Enfrentamiento entre los derechos de libertad de expresión, honra y reputación a la luz del sistema interamericano de protección de derechos humanos. Por regla general, cualquier forma de manifestación discursiva está amparada por el derecho a la libertad de expresión, indistintamente del grado de aceptación o repudio que cause en la sociedad. En este sentido, la Relatoría Especial para la Libertad de Expresión de la Comisión Interamericana de Derechos Humanos, en el informe llamado Marco jurídico interamericano sobre el derecho a la Llbertad de expresión (2009), manifestó lo siguiente:}

De particular importancia es la regla según la cual la libertad de expresión debe garantizarse no sólo en cuanto a la difusión de ideas e informaciones recibidas favorablemente o consideradas inofensivas o indiferentes, sino también en cuanto a las que ofenden, chocan, inquietan, resultan ingratas o perturban al Estado o a cualquier sector de la población. Así lo exigen el pluralismo, la tolerancia y el espíritu de apertura, sin los cuales no existe una sociedad democrática. (p. 21)

Es indispensable que la protección del derecho a la libertad de expresión se encuentre extendida incluso a aquellas opiniones que no gozan del beneplácito de la mayoría, ya que ello impide el surgimiento de manifestaciones de intolerancia dentro de una sociedad donde todas las personas tienen derecho a expresarse.

En cuanto a la confrontación entre el derecho a la libertad de expresión y el derecho a la honra, es importante anotar que estos derechos mantienen la misma jerarquía, de tal suerte que un enfrentamiento entre ambos no puede resolverse dando prioridad a 
uno en detrimento del otro. Por lo tanto, no debe haber una preferencia o tendencia a dar prelación a un derecho sin realizar un estudio de fondo sobre cada caso en particular, porque se puede incurrir en uno de dos errores: por un lado, permitir las afrentas contra el honor y el buen nombre y, por otro lado, propiciar escenarios de censura bajo el pretexto de brindar una protección "eficiente" hacia los derechos contrapuestos. Por esta razón, la CIDH (2009) expresó lo siguiente:

El honor de los individuos debe ser protegido sin perjudicar el ejercicio de la libertad de expresión ni el derecho a recibir información. Cuando se presenta en un Estado una tendencia o patrón en el sentido de preferir el derecho a la honra sobre la libertad de expresión y restringir esta última cuando existe tensión, en todo caso, se violenta el principio de armonización concreta que surge de la obligación de respetar y garantizar el conjunto de derechos humanos reconocidos en la Convención Americana. (p. 46)

De lo anterior se colige que, cuando existe un conflicto que involucra a los derechos mencionados, se debe tomar una decisión cuidadosa que analice las necesidades de satisfacción de cada uno de estos y propenda por una solución lo menos restrictiva posible. De lo contrario, se estaría frente a un escenario evidente de vulneración de derechos en atención a las predilecciones de cada Estado y de sus operadores judiciales.

\section{DERECHOS A LA LIBERTAD DE EXPRESIÓN, HONRA Y BUEN NOMBRE EN LA JURISPRUDENCIA DE LA CORTE CONSTITUCIONAL}

Luego de finalizar el breve recorrido ilustrativo sobre la importancia que tienen los derechos que son objeto de este estudio en el campo del derecho internacional de los derechos humanos, se desciende al derecho doméstico colombiano. Si bien la libertad de expresión, la honra y el buen nombre son derechos fundamentales nominados en la Constitución Política de Colombia, es importante resaltar que la interpretación que la Corte Constitucional ha hecho respecto de estos es crucial a la hora de determinar sus alcances, limitaciones y composiciones.

\subsection{Derecho fundamental a la libertad de expresión}

La jurisprudencia constitucional ha entendido el derecho a la libertad de expresión como una categoría genérica que contiene varios derechos y libertades (Sentencia T-200/18, 2018). Los elementos específicos que integran este concepto genérico son los siguientes: la libertad de opinión, o también conocida como libertad de expresión stricto sensu; la libertad de informar y de recibir información; y la libertad de fundar medios de comunicación. A través de la Sentencia T-117/18 (2018) la Corte se refirió a la diferencia entre la libertad de información y la libertad de opinión en los siguientes términos: 
La libertad de expresión comprende dos aspectos distintos, a saber: la libertad de información, orientada a proteger la libre búsqueda, transmisión y recepción de información cierta e imparcial sobre todo tipo de situaciones o hechos, y la libertad de opinión, entendida como libertad de expresión en sentido estricto, la cual implica básicamente la posibilidad de poder difundir o divulgar, a través de cualquier medio de comunicación, las propias ideas, opiniones y pensamientos. (Sentencia T-117/18, 2018)

Para el ejercicio de la libertad de opinión solo son requeridos los medios físicos e intelectuales con los que cuenta aquella persona que expresa sus sentimientos, emociones y pensamientos. Por otro lado, para el ejercicio de la libertad de información es requisito indispensable que el contenido difundido cumpla con parámetros precisos de veracidad e imparcialidad.

En lo que respecta a la libertad de opinión es importante resaltar que, aun en aquellos eventos en los cuales es ejercida a través de medios de comunicación, el canal por medio del cual se emite el mensaje no desdibuja su real naturaleza. Por esta razón, no es dable exigir parámetros de veracidad e imparcialidad cuando quien se expresa lo hace a través de una columna de periódico o de revista, siempre y cuando se trate de libertad de opinión y no de información.

\subsection{Derechos fundamentales a la honra y al buen nombre: similitudes y diferencias}

La honra es un derecho fundamental que encuentra sustento en el artículo 21 de la Constitución Política de Colombia y, de acuerdo con la jurisprudencia constitucional, "alude a la consideración que sobre la persona se haga en razón a su condición de ser humano, por su valor intrínseco" (Sentencia T-731/15, 2015). Por otro lado, el derecho al buen nombre es entendido como "la buena opinión o fama adquirida por un individuo en razón a la virtud y al mérito, como consecuencia necesaria de las acciones protagonizadas por él" (Sentencia T-411/95, 1995). A través de la Sentencia C-442/11 (2011) la Corte Constitucional se refirió a las diferencias entre estos derechos de la siguiente manera:

El buen nombre alude a la reputación de la persona, es decir, a la apreciación que la sociedad emite de la persona por su comportamiento en ámbitos públicos. Mientras que la honra, por su parte, se refiere a la valoración de comportamientos en ámbitos privados, así como la valoración en sí de la persona. En suma, el buen nombre se refiere a la apreciación que se otorga a la persona por asuntos relacionales (cumplimiento de obligaciones dinerarias, aptitud para dirigir un equipo deportivo, entre otras), mientras que la honra se refiere más a la apreciación de la sociedad hacia una persona, a partir de su propia personalidad y comportamientos privados directamente ligados con ella. (Sentencia C-442/11, 2011)

Ahora bien, analizados y descritos los derechos fundamentales que han de tenerse en cuenta al momento de la identificación de las relaciones de precedencia condicionada, en los casos concretos en la jurisprudencia de la Corte Constitucional, se procederá a hacer un breve pronunciamiento respecto del principio de armonización. 
Es importante resaltar que, el objetivo esencial de este principio es evitar que en las colisiones entre derechos fundamentales se sacrifique un derecho para darle prevalencia a otro bajo argumentos simples o carentes de lo que Alexy (1993) denomina una razón iusfundamental correcta.

\section{PRINCIPIO DE ARMONIZACIÓN EN LA JURISPRUDENCIA DE LA CORTE CONSTITUCIONAL COLOMBIANA}

Al presentarse un enfrentamiento entre el derecho a la libertad de expresión (en cualquiera de sus manifestaciones) y el derecho a la honra, o el derecho al buen nombre, evidentemente se está ante una disputa de derechos que gozan de una misma jerarquía constitucional. De ahí que la colisión deba solucionarse de forma armónica, esto es, de manera que integre todas las disposiciones constitucionales para lograr la eficacia de cada derecho. Para la resolución de estos conflictos existe el llamado principio de armonización concreta que, de acuerdo con lo establecido por la Corte Constitucional mediante la Sentencia T-425/95 (1995), cumple la siguiente función:

Impide que se busque la efectividad de un derecho mediante el sacrificio o restricción de otro. De conformidad con este principio, el intérprete debe resolver las colisiones entre bienes jurídicos, de forma que se maximice la efectividad de cada uno de ellos. (Sentencia T-425/95, 1995)

Este tipo de casos no pueden resolverse de manera apresurada a través de una ponderación superficial, sino que exigen un análisis mayor que sopese "los diversos bienes e intereses en juego y propender su armonización en la situación concreta, como momento previo y necesario a cualquier jerarquización o prevalencia de una norma constitucional sobre otra" (Sentencia T-425/95, 1995).

De acuerdo con los postulados de la Corte Constitucional (1995), la armonización significa una delimitación de los bienes jurídicos que se contraponen. Por lo tanto, las limitaciones planteadas para cada caso en particular tienen que ser proporcionales, la proporcionalidad hace referencia a la "comparación de dos variables relativas, cuyos alcances se precisan en la situación concreta, y no a la ponderación entre una variable constante o absoluta, y otras que no lo son" (Sentencia T-425/95, 1995). Esto se debe a que, de lo contrario, no tendría ningún sentido estudiar el asunto, ya que siempre se sabría cuál es el derecho al que se le dará prelación.

\section{REGLAS Y PRINCIPIOS}

Cuando se aborda la teoría de los derechos fundamentales es importante tener en cuenta la distinción entre las reglas y los principios, puesto que a pesar de que ambos conceptos hacen referencias a normas porque "dicen lo que debe ser" (Alexy, 1993, p. 83), además, están encaminados a permitir o prohibir algo. Lo cierto es que no son lo mismo, por lo tanto, esta diferenciación se puede analizar si se parte de la idea de que se trata de una "distinción entre dos tipos de normas" (Alexy, 1993, p. 83). 
Para establecer la diferencia entre reglas y principios, Alexy (1993) analiza algunos criterios que pueden hacer visible tal distinción. Dentro de estos se encuentra el criterio del alto o bajo grado de generalidad, el cual hace referencia a que las normas catalogadas como derechos fundamentales, que constituyen principios, tienen un amplio grado de generalidad respecto de aquellas que son catalogadas como reglas, que contienen un nivel de generalidad más bajo. Así, por ejemplo, aquella norma que dice que "toda persona goza de libertad religiosa" (Alexy, 1993, p. 83) tiene un espectro más general y, por lo tanto, será principio. En cambio, aquella que establece que "todo preso tiene derecho a convertir a otros presos" (Alexy, 1993, p. 83) reduce su campo de acción y, por ende, se entenderá como una regla.

La enunciación de este parámetro en la obra de Alexy se hace a título ilustrativo, pero no es la tesis con la que el autor considera que se hace una verdadera distinción entre estos tipos de normas, ya que, según su criterio, no solo es necesario observar el mayor o menor grado de generalidad, sino que este problema debe ser analizado desde una perspectiva cualitativa. Por esta razón, expresa lo siguiente:

El punto decisivo para la distinción entre reglas y principios es que los principios son normas que ordenan que algo sea realizado en la mayor medida posible, dentro de las posibilidades jurídicas y reales existentes. Por lo tanto, los principios son mandatos dé optimización, que están caracterizados por el hecho de que pueden ser cumplidos en diferente grado y que la medida debida de su cumplimiento no sólo depende de las posibilidades reales, sino también de las jurídicas. El ámbito de las posibilidades jurídicas es determinado por los principios y reglas opuestos. (Alexy , 1993, p. 86)

Mientras que las reglas son normas que contienen un mandato definitivo, es decir, se aplican o no se aplican en un caso concreto, sus determinaciones son aplicables a un ámbito fáctico y jurídicamente posible. Es por esto que Alexy (1993) llega a la conclusión de que "la diferencia entre reglas y principios es cualitativa y no de grado" (p. 87) y, por lo tanto, toda norma es una regla o un principio.

\subsection{Colisión entre principios}

Existen innumerables situaciones en las cuales un principio (mandato de optimización que debe cumplirse en la mayor medida de las posibilidades) colisiona con otro principio que, de ser aplicado, comporta una decisión final opuesta al primero. Cuando esto sucede no es viable pensar en la eliminación de uno de los principios declarándolo inválido para darle prevalencia al otro, ni buscar la manera de crear una regla que sirva de excepción a la aplicación de uno respecto del otro, puesto que aquí no se aborda el conflicto desde el punto de vista de la validez de los principios en cuestión, toda vez que se entiende que ambos son válidos, sino que se requiere que uno preceda al otro, y para determinar cuál debe preceder es indispensable saber cuál es el principio que tiene un mayor peso al ser aplicado en un caso concreto. 
De acuerdo con Alexy (1993) la colisión entre principios debe ser resuelta a través de la ponderación, la cual dará como resultado una "relación de precedencia condicionada" (Alexy, 1993, p. 92) entre los principios implicados. A continuación, se ejemplificará la construcción de esta relación:

Juan hizo una serie de afirmaciones en la radio donde expresó que José era una persona en la que no se podía confiar.

Pl: Se garantiza a toda persona la libertad de expresar y difundir sus pensamientos y opiniones.

P2: Se garantiza el derecho al buen nombre.

Si se le da prevalencia al principio Pl ello implica que Juan está en la libertad de expresar y difundir sus pensamientos y opiniones en el caso concreto. Por otro lado, si se le da prevalencia al principio P2 significa que el derecho al buen nombre de José es privilegiado. De esta manera, acoger cualquiera de los dos principios trae como consecuencia un juicio completamente opuesto.

Si se llega a comprobar que el principio Pl tiene un peso mayor que el principio P2 en su aplicación en un caso específico, y existen razones correctas que respaldan esa posición, entonces se crea una condición de precedencia que puede ser identificada como C. Teniendo como resultado que, P1 precederá a P2 siempre y cuando en el caso concreto se estén dando las circunstancias C.

Para el ejemplo que se ha creado, podría decirse que $C$ equivale a la siguiente condición: "si la afirmación del sujeto activo está enmarcada en una opinión que deriva de sus intimas convicciones producto de situaciones que ha vivido, entonces el principio P1 (libertad de expresión) precederá al principio P2 (derecho al buen nombre)". Por lo tanto, C implica una condición de precedencia que contiene un supuesto de hecho y una consecuencia jurídica, es decir, si C $\rightarrow$ R. Esto significa que, de cumplirse el supuesto de hecho de $\mathrm{C}$ en un caso concreto, en donde colisionen los principios P1 y P2, se dará como resultado R (prevalencia del principio P1).

\section{ESTRUCTURA DE LA PONDERACIÓN}

El surgimiento de una relación de precedencia condicionada es el resultado de una ponderación, pues a través de esta se evita que la relación de precedencia sea vista como una simple regla derivada de la subjetividad del juzgador. Así mismo, Alexy (1993) plantea que:

La ponderación es todo menos un procedimiento abstracto o general. Su resultado es un enunciado de preferencia condicionado que, de acuerdo con la ley de colisión, surge de una regla diferenciada de decisión. Ya del concepto de principio resulta que en la ponderación no se trata de una cuestión de o-todo-o-nada, sino de una tarea de optimización. (p. 166) 
Empero, diversas voces coinciden en que cuando se busca ponderar el enfrentamiento o colisión entre dos principios no existen fórmulas exactas, y a pesar de que Alexy dispone de la llamada fórmula de peso para resolver este tipo situaciones, de acuerdo con la postura de los críticos, esta no resulta del todo satisfactoria debido a que la subjetividad del juzgador siempre será un factor determinante a la hora de elegir a cuál principio se le dará prevalencia. En apoyo a lo anterior, se resalta lo planteado por García Amado (2016) en su crítica a los postulados de Manuel Atienza (quien a su vez defiende las posiciones Alexyanas) donde afirma que:

Nunca se pondera para perder. Jamás veremos o leeremos entre líneas, en los "ponderativos", una expresión así: la solución que a mí me parece más justa y aceptable es la solución S, pero después de ponderar he comprobado que pesa más el principio que lleva a la solución S-. (p. 76)

Pese a la existencia de una multiplicidad de críticos en contra de la ponderación, lo cierto es que las nuevas tendencias del constitucionalismo moderno la siguen mostrando como la herramienta por excelencia para resolver este tipo de colisiones. Así, por ejemplo, Bernal Pulido (2006) aboga por las ideas de Alexy replicando que la estructura de la ponderación se sirve de tres elementos: i) la ley de la ponderación; ii) la fórmula del peso; y iii) la carga de la argumentación. Esta última es utilizada cuando se presentan empates al hallar el peso concreto de cada principio.

\subsection{La ley de la ponderación}

Según la ley de la ponderación de Alexy (1993), al presentarse una colisión entre dos principios fundamentales hay que tener en cuenta que "cuanto mayor es el grado de la no satisfacción o de afectación de un principio, tanto mayor tiene que ser la importancia de la satisfacción del otro" (p. 161).

Para realizar un buen ejercicio ponderativo es importante tener en cuenta tres variables fundamentales: i) la importancia de la satisfacción de un principio; ii) el peso abstracto de los principios; y iii) el reconocimiento de las apreciaciones empíricas. Los dos primeros pasos pueden ser resueltos a través de lo que Alexy (1993) llama la escala triádica, es decir, se establece un grado de intensidad catalogado en leve (mínimo), moderado (medio) y grave (máximo) que hace referencia al grado de importancia de los principios en colisión.

En ese sentido, la primera variable de la ponderación debe dividirse en tres pasos:

1. "Definir el grado de la no satisfacción de uno de los principios" (Bernal Pulido, 2006, p. 62).

2. Definir la importancia de satisfacer el principio contrario.

3. Saber si la importancia de satisfacer uno de los principios justifica la afectación o no satisfacción del otro. 
En cuanto a la otra variable relativa al peso abstracto, es importante tener en cuenta que cada principio puede poseer un grado jerárquico mayor al otro dentro de un ordenamiento constitucional. En este sentido, se trae a colación el ejemplo de Bernal Pulido (2006) cuando establece que "el principio de protección de la vida tiene un peso abstracto mayor que la libertad, por cuanto, es obvio, para poder ejercer la libertad es necesario estar vivo" (p. 63).

Por último, existe la variable sobre la seguridad o certeza de las apreciaciones empíricas, la cual se basa "en el reconocimiento de que las apreciaciones empíricas relativas a la importancia de los principios en colisión pueden tener un grado diverso de certeza y esto puede afectar el peso relativo que se atribuya a cada principio en la ponderación" (Bernal Pulido, 2006, p. 63).

\subsection{La fórmula del peso}

Para la articulación de las tres variables antes expuestas existe la llamada fórmula del peso, mediante la cual se establece el peso concreto del principio Pl en relación con el principio P2 y viceversa, para determinar cuál principio ha de preceder al otro en un caso concreto. Para una mayor compresión de la formula se emplearán letras de acuerdo con las iniciales de sus elementos y se señalará el valor que debe dársele a cada uno.

ISP = Importancia de la satisfacción del principio. Se mide en: leve (1), medio (2) y grave (4).

$\mathrm{PA}=$ Peso abstracto. Se mide en: leve (1), medio (2) y grave (4).

$\mathrm{SAE}=$ Seguridad de las apreciaciones empíricas. Se mide en: cierto (1), plausible (0.5) y falso (0.25).

$$
\begin{gathered}
\text { P1 en relación con P2 }=\frac{\text { ISP P1 X PA P1 X SAE P1 }}{\text { ISP P2 X PA P2 X SAE P2 }} \\
\text { P2 en relación con P1 }=\frac{\text { ISP P2 X PA P2 X SAE P2 }}{\text { ISP P1 X PA P1 X SAE P1 }}
\end{gathered}
$$

Posteriormente, se pasa a reemplazar las letras por los valores numéricos que representan el grado de intensidad con el cual se ven reflejados los elementos de la fórmula en el caso concreto, para luego obtener un resultado cuantitativo que determinará el principio que ha de prevalecer.

$$
\mathrm{P} 1 \text { en relación con } \mathrm{P} 2=\frac{4 \times 4 \times 1}{2 \times 2 \times 1}=\frac{16}{4}
$$




$$
\begin{aligned}
\frac{16}{4} & =\mathbf{4} \\
\text { P2 en relación con } \mathrm{Pl} & =\frac{2 \times 2 \times 1}{4 \times 4 \times 1}=\frac{4}{16} \\
\frac{4}{16} & =\mathbf{0 , 2 5}
\end{aligned}
$$

Resultado: el principio P1 precede al principio P2 en este caso concreto.

\section{RELACIONES DE PRECEDENCIA RESULTANTES DE LAS COLISIONES ENTRE LOS PRINCIPIOS: LIBERTAD DE EXPRESIÓN, HONRA Y BUEN NOMBRE EN LA JURISPRUDENCIA DE LA CORTE CONSTITUCIONAL COLOMBIANA}

En este acápite se expondrán las relaciones de precedencia condicionada identificadas en la jurisprudencia de la Corte Constitucional donde se han resuelto casos que involucraron colisiones entre los principios libertad de expresión, honra y buen nombre derivados de actividades periodísticas en el periodo comprendido entre 1998 y 2019. Para efecto de ilustrar las relaciones de precedencia se entenderá que Pl es igual a libertad de expresión y P2 es igual a honra y buen nombre.

\subsection{T-066 de 1998}

El primer asunto que se expone es la Sentencia T-066/98 (1998), aquí la Corte Constitucional revisó el caso del alcalde de un municipio de Colombia que se vio afectado por una publicación de la revista Semana en la que se le incluía en una lista con los alcaldes que supuestamente tenían vínculos con grupos guerrilleros. En esta oportunidad, la Corporación decidió darle prevalencia a los principios de honra y buen nombre, pues la información difundida no cumplía con los parámetros de veracidad e imparcialidad. La revista Semana no intentó demostrar las distintas versiones sobre los hechos que componían la noticia, de ahí que la Corte expresara lo siguiente:

No cumplir con este procedimiento constituye una imprudencia, una negligencia grave, que, en este caso, vulneró el derecho de los ciudadanos a contar con una información veraz e imparcial, afectó la honra y buen nombre de los alcaldes y puso en condiciones de riesgo la vida e integridad personal de los últimos. (Sentencia T-066/98, 1998)

Así las cosas, la relación de precedencia establecida fue la siguiente: P2 precede a $\mathrm{Pl}$ en el caso concreto, toda vez que la noticia difundida no cumplía con los paramentos de veracidad e imparcialidad. 


\subsection{SU-1723 de 2000}

A través de la Sentencia SU-1723/00 (2000), la Corte revisó el caso de la tutela interpuesta por el cantante Diomedes Díaz en contra del medio de comunicación Telecolombia Ltda por la emisión de un programa de televisión donde se hizo alusión a los hechos que rodearon la muerte de una mujer y el proceso penal en el que el accionante se encontraba inmerso. En esta oportunidad, la alta corporación procedió a elaborar una relación de precedencia donde prevaleció el derecho a la libertad de expresión.

En ese sentido, la relación de precedencia establecida fue la siguiente: Pl precede a P2 en el caso concreto, ya que en la difusión de la noticia se respetó el principio de veracidad e imparcialidad y se asumió una posición neutral.

\subsection{T-634 de 2001}

Mediante la Sentencia T-634/01 (2001), la Corte Constitucional revisó el caso de la acción de tutela presentada por un contralmirante de la Armada Nacional en contra de la extinta revista Cambio, por cuanto esta realizó una publicación en la que se hacía referencia a los presuntos vínculos que el accionante tuvo con una persona cercana al narcotráfico.

Este caso tiene unas particularidades en lo que respecta a la creación de la relación de precedencia condicionada que permitió establecer una prevalencia del principio de libertad de expresión. En esta oportunidad, la Corte se topó con un escenario en el cual se mezclaron elementos informativos propios de la actividad periodística y de opiniones personales del periodista que realizó la publicación, cuestión que, por lo general, hace difícil evidenciar el cumplimiento de los requisitos de veracidad e imparcialidad propios de la libertad de prensa. No obstante, la alta corporación se pronunció en los siguientes términos:

Si bien el artículo en cuestión mezcla y entrelaza hechos objeto de la información con las opiniones, interpretaciones y demás expresiones periodísticas referidas a la situación en comento, con todo el material recopilado y publicado dentro del mismo artículo se permite y otorga la posibilidad al lector o público en general, de diferenciar claramente qué información es producto del material investigativo y qué forma parte de la opinión periodística. (Sentencia T-634/01, 2001)

Y concluyó que,

Con la publicación del material objeto de la información se permite a la opinión pública establecer la diferencia entre hechos y opiniones, formándose así mismo su propia opinión o criterio sobre los hechos, lo que no implica que el medio no pueda libremente expresar su pensamiento y opinión sobre los mismos. (Sentencia T-634/01, 2001)

Así las cosas, la Corte estableció una relación de precedencia que se puede ilustrar de la siguiente forma: Pl precede a P2 en el caso concreto, ya que a pesar de que la 
noticia difundida mezcló elementos propios del derecho a la información y del derecho a la opinión, cumplió con los parámetros de veracidad e imparcialidad y le permitió al destinatario formarse su propio criterio.

\section{4. $T-219$ de 2009}

En esta sentencia, la Corte Constitucional revisó el caso de la tutela presentada por un magistrado del Consejo Superior de la Judicatura en contra de la revista Semana, luego de que este medio de comunicación publicara una noticia en la que se hacía referencia a los lazos de amistad que el accionante tenía con una persona que a su vez sostenía negocios con un extraditable. La publicación incurrió en muchas imprecisiones, dentro de las más destacadas se encuentran las siguientes: se hizo pasar a un sujeto como patrocinador de eventos para agasajar a algunos magistrados de Colombia; se citarón unas palabras de elogio pronunciadas por el accionante indicándose un lugar y fecha de emisión incorrectos; se descontextualizaron elementos fácticos; y se hicieron pasar opiniones por hechos verdaderos. De esta manera, se desconocieron los requisitos de veracidad e imparcialidad establecidos en el artículo 20 la Constitución Política de Colombia, cuestión que inducía en error a los destinatarios de la revista, al tiempo que vulneraba los derechos fundamentales a la honra y al buen nombre del accionante, de tal suerte que la Corte manifestó lo siguiente:

Por la forma en que el artículo fue redactado, las conclusiones personales de los periodistas se presentan como hechos realmente ocurridos, lo cual, como se vio, dista por completo de la realidad probada en el proceso. Por lo tanto, existió un desconocimiento de los principios del artículo 20 de la Carta y, en consecuencia una vulneración de los derechos a la honra y buen nombre del demandante. (Sentencia T-219/09, 2009)

Así las cosas, la alta corporación estableció una relación de precedencia condicionada orientada a dar prevalencia a la honra y al buen nombre, la cual se ilustra a continuación: P2 precede a Pl en este caso concreto, por cuanto el medio de comunicación presentó conclusiones personales como hechos ciertos y desconoció los requisitos de veracidad e imparcialidad.

\section{5. $T-043$ de 2011}

Mediante la Sentencia T-043/11 (2011), la Corte Constitucional revisó el fallo proferido en el trámite de acción de tutela iniciado por la sociedad Barón Peralta Ltda (centro médico El Cabrero), Isaac Gabriel Meza Lozano y Justiniano Macías Cárdenas en contra de Caracol Televisión y el programa Séptimo Día. De acuerdo con los elementos fácticos narrados en el caso, el programa de televisión vulneró el derecho al buen nombre de los actores cuando decidió hacer un reportaje, donde afirmaba que la clínica mantenía recluido a un ciudadano italiano bajo el argumento de que presentaba problemas mentales para evitar que fuera enviado a una prisión y, así, propiciar la impunidad. La Corte se refirió al asunto expresando lo siguiente: 
La libertad de información implica una carga de veracidad e imparcialidad al momento de su transmisión. En este sentido, tanto la veracidad como la imparcialidad referida a los hechos objeto de la información deben siempre ser posibles de comprobarse por el medio. (Sentencia T-043/11, 2011)

Así las cosas, concluyó que el medio de comunicación no vulneró el derecho al buen nombre de los accionantes, argumentando que:

De la descripción hecha se concluye que el programa emitido no afectó en forma alguna el derecho al buen nombre del Centro Médico. En efecto, del material probatorio no se deduce que la información trasmitida en el programa sea falsa, o presente un punto de vista que rebase los amplios parámetros dentro de los cuales debe valorarse la imparcialidad de un medio de comunicación. (Sentencia T-043/11, 2011)

En ese sentido, la alta corporación estableció una relación de precedencia encaminada a dar prevalencia al principio de libertad de expresión, la cual se ilustra a continuación: P1 precede a P2 en el caso concreto, toda vez que el medio de comunicación difundió la información cumpliendo con la carga de veracidad e imparcialidad que le es exigida para tal fin.

\section{6. $T-312$ de 2015}

En esta sentencia, la Corte Constitucional revisó el fallo emitido en el trámite de tutela iniciado por el fiscal Jesús Aureliano Gómez Jiménez en contra del Canal Caracol y el programa Séptimo Día. El fiscal consideró que sus derechos fundamentales a la honra y al buen nombre habían sido vulnerados por la emisión de un programa documental en el que se cuestionaba su labor como fiscal encargado de la investigación de la muerte de dos menores de edad en la ciudad de Medellín.

Para la tomar una decisión la Corte verificó el cumplimiento de los requisitos de veracidad e imparcialidad en la difusión de la información, y pudo determinar que el medio de comunicación indagó más allá del simple relato de los familiares de las víctimas, pues le solicitó explicaciones a un investigador de CTI, al juez que tuvo conocimiento del asunto y al fiscal (accionante), siendo este último el único que se negó a dar respuesta a las preguntas formuladas por el periodista del canal. Teniendo estos puntos de referencia, la Corte manifestó expresamente lo siguiente:

Esta Corporación valora positivamente que también se haya acudido a un experto forense con el objetivo de contar con un concepto técnico e imparcial de los hechos. En esta medida, Séptimo Día no presentó una versión unilateral, acabada y pre-valorada, sino un trabajo periodístico legítimo. (Sentencia T-312/15, 2015)

En ese sentido, el órgano colegiado aplicó la relación de precedencia que se expone a continuación: P1 precede a P2, en el caso concreto, toda vez que el programa de televisión tuvo en consideración las declaraciones de las distintas partes y le brindó la oportunidad al accionante para que explicara su proceder. Por lo tanto, 
no mostró una versión unilateral de los hechos, cuestión que permite acreditar el cumplimiento de los requisitos de veracidad e imparcialidad.

\section{7. $T-731$ de 2015}

La Sentencia T-731/15 (2015) guarda cierta similitud con la Sentencia T-634/01 (2001), en lo que respecta a la mezcla de elementos propios de la libertad de información y de la libertad de opinión en un mismo escenario periodístico. De tal suerte que su estudio requiere de un mayor detenimiento, ya que puede ser entendida como una actualización de lo planteado en el año 2001 sobre este tipo de situaciones.

En esta sentencia, la Corte Constitucional estudió el caso de la acción de tutela presentada por los hermanos Juan Manuel y Carlos Fernando Galán en contra de la fundación Las 2 Orillas, propietaria del informativo digital de mismo nombre, y del periodista Gustavo Rúgeles, por la publicación de una columna en la que se hicieron una serie de afirmaciones sobre el éxito contractual de la Corporación Escuela Galán para el Desarrollo de la Democracia durante el gobierno de Juan Manuel Santos y el coetáneo triunfo de los hermanos en el Senado de la República. Según el criterio de los demandantes, la publicación vulneraba sus derechos fundamentales a la honra y al buen nombre porque daba información descontextualizada que confundía al lector, además aseguraron que ni ellos ni su familia tenían relación con la entidad, la cual es de carácter mixto, cuyo porcentaje de participación estatal es del 85.57 \% frente a un $14.23 \%$ de origen privado.

El Juzgado Tercero Civil del Circuito de Bogotá tuvo el conocimiento del asunto en primera instancia y decidió conceder el amparo solicitado por los demandantes, argumentando que la nota periodística contenía "opiniones fundadas en hechos inexactos", situación agravada por la amplia difusión que se le dio a la columna. El a quo consideró que a los demandantes se les atribuyó el éxito que obtuvo la corporación con la celebración de los contratos que se mencionaban. Además, manifestó que el periodista incumplió con los requisitos de veracidad e imparcialidad necesarios para el ejercicio del derecho a la información, ya que sin realizar una investigación adecuada sobre la persona jurídica que analizaba concluyó la participación de los accionantes en la misma y que la contratación de la corporación era resultado de la acción política de estos.

El medio de comunicación accionado presentó un escrito de impugnación, cuyo conocimiento estuvo en cabeza de la Sala Séptima de Decisión Civil del Tribunal Superior del Distrito de Bogotá. Luego de analizar la nota periodística, el ad quem determinó que esta correspondía a una opinión personal del periodista que tenía como fundamento una investigación que había realizado respecto de la contratación de algunas entidades con la Corporación Escuela Galán para el Desarrollo de la Democracia. Por lo tanto, se trataba de libertad de expresión stricto sensu y recordó que frente a esta la Corte Constitucional ha determinado que no se requieren parámetro de veracidad e imparcialidad. Además, 
hizo énfasis en que los accionantes son servidores públicos que representan sectores políticos y, por ende, la ciudadanía en general y los medios de comunicación pueden ejercer vigilancia sobre las actividades que realizan en la vida pública con opiniones que incluso pueden ser equivocadas o parcializadas. En atención a todo lo anterior, el juzgador de segundo grado decidió revocar la sentencia del Juzgado Tercero Civil del Circuito de Bogotá y denegar el amparo solicitado por los accionantes.

Cuando el caso pasó a la Corte Constitucional para su eventual revisión, esta optó por confirmar la sentencia de la Sala Séptima de Decisión Civil del Tribunal Superior del Distrito de Bogotá. Sin embargo, al momento de descender al caso concreto, la Corte determinó que la columna objeto de análisis no contaba con una naturaleza homogénea, ya que mezclaba elementos de la libertad de información (libertad de expresión lato sensu) con elementos de la libertad de opinión (libertad de expresión stricto sensu). Por lo tanto, no era viable exigir únicamente cargas específicas de una de las dos libertades, lográndose identificar que los apartes de la columna que hacían referencia a información fueron corroborados por el periodista a través de un proceso investigativo, lo que a su vez evidenciaba el cumplimiento del requisito de veracidad, mientras que la opinión brindada cumplía con los siguientes criterios:

(i) se basa en hechos ciertos y verificables, por lo que no tiene la virtualidad de generar un impacto negativo frente al prestigio social y al reconocimiento público del que los accionantes gozan; (ii) la opinión no se presenta de un modo tal que pretenda hacerse pasar como un hecho cierto, por lo que tampoco busca engañar al lector; (iii) la presentación de las opiniones como tales permiten al público tomarlas de acuerdo con su buen criterio y con ello conformar su opinión libremente. (Sentencia T-731/15, 2015)

A continuación, se ilustra la relación de precedencia que estableció la Corte para este caso concreto en donde la actividad del periodista mezcló elementos de libertad de información y de libertad de opinión: P1 precede a P2 en el caso concreto, toda vez que se cumplieron las cargas de veracidad e imparcialidad en la presentación de la información, y esta representó una opinión relevante desde el punto de vista político, que no se confundió con hechos ni impactó negativamente los derechos invocados por los accionantes.

\section{8. $T-117$ de 2018}

En esta sentencia se acumularon dos expedientes que contienen elementos fácticos muy similares. Sin embargo, para lo concerniente al tema que es objeto de estudio de este artículo, solo resulta pertinente el análisis de la relación de precedencia creada en el expediente T-6.155.024, teniendo en cuenta que esta hace alusión a la colisión de los principios libertad de expresión, honra y buen nombre derivados de la actividad periodística, mientras que el otro caso identificado bajo el expediente T-6.371.066 plantea una problemática parecida pero que no involucra el ejercicio periodístico. 
Dentro de los supuestos de hecho más relevantes del caso, se tiene que la señora Gloria Mayorga quien se desempeñaba como juez promiscuo municipal de Sesquilé (Cundinamarca) interpuso una acción de tutela en contra del periodista Aldemar Solano y de la señora Nasly Huertas, por considerar vulnerados sus derechos fundamentales a la honra, al buen nombre y a la imagen. El señor Solano realizó una publicación en su cuenta de Facebook y en un blog de noticias de un escrito titulado "denuncian acoso y matoneo por parte de la juez de Sesquilé", donde se hacía referencia a presuntos tratos indebidos de la funcionaria con sus empleados, las denuncias penales y disciplinarias de las que había sido objeto y los inconvenientes que esta había tenido en un conjunto residencial. La publicación a su vez fue comentada y respaldada por la señora Nasly Huertas.

La Corte Constitucional (2018) al momento de revisar el caso abordó el asunto señalando que, si bien los periodistas pueden denunciar hechos y actuaciones que puedan constituir delitos o faltas disciplinarias, sin que para ello estén obligados a esperar la producción de un fallo definitivo, deben ser muy cuidadosos en la información difundida, puesto que no pueden inducir a sus receptores a que den por cierto hechos que aún no han sido del todo corroborados, además, manifestó que:

Los interrogantes planteados en la publicación ahora cuestionada, tienen como consecuencia sugerir al lector que la accionante es una persona que incurre en conductas reprochables disciplinaria y penalmente, sin que las autoridades competentes se hayan pronunciado al respecto, pues las pruebas obrantes en el expediente, aunque dan cuenta de la existencia de algunos procesos en contra de la accionante, en ninguno de ellos se ha proferido una decisión de fondo que corrobore lo expresado por el accionado [...] la información presentada sin la suficiente exactitud que permita verificar la verdad de los hechos y evitar a la confusión del lector, desconoce el principio de veracidad. (Sentencia T-117/18, 2018)

En ese sentido, la Corte optó por darle prevalecía a los principios honra y buen nombre, estableciendo una relación de precedencia que se puede ilustrar de la siguiente manera: P2 precede a P1 en el caso concreto, toda vez que la información fue presentada sin la suficiente exactitud que permitiera verificar la verdad de los hechos y evitar la confusión del lector, desconociendo el principio de veracidad.

\section{9. $T-200$ de 2018}

A través de la Sentencia T-200/18 (2018) también se decidieron dos expedientes. Sin embargo, solo se analizará el caso identificado en el expediente T-6.433.282, puesto que en este se plantea la colisión concreta de los principios bajo estudio, mientras que en el caso del expediente T-6.442.273 el análisis se centra en el derecho a la intimidad de los menores de edad. Aclarado esto, se procede a hacer una breve síntesis de los elementos fácticos del primer caso. 
El día 14 de enero del año 2017, el señor Santos Aguillón Guarín se movilizaba por el municipio de Jericó en el departamento de Boyacá en un carro que era conducido por su hijo. El vehículo chocó con otro carro que transitaba por el sector, lo que generó la presencia de las autoridades de policía en el lugar, estas le preguntaron a Aguillón si portaba algún tipo de arma de fuego, a lo que el señor respondió afirmativamente y procedió a hacer la entrega de la misma a los agentes. Posteriormente, el 16 de enero de 2019 el Diario Extra, de frecuente circulación en el municipio de Jericó y en otros municipios vecinos, publicó una noticia donde informaba que la Policía Nacional había incautado a Aguillón un arma de fuego por encontrarse en estado de embriaguez. Una vez Aguillón tuvo conocimiento de esta información presentó una solicitud de rectificación al medio de comunicación, manifestando que no fue detenido por consumir bebidas alcohólicas ni por hacer actos delincuenciales. Sin embargo, el medio de comunicación hizo caso omiso a la solicitud, razón por la cual el afectado presentó una acción de tutela en contra de este medio por considerar vulnerados sus derechos al buen nombre, a la honra, a la rectificación y de petición.

Al revisar el caso, la Corte Constitucional procedió a amparar los derechos fundamentales a la honra y al buen nombre del accionante, argumentando que de "los elementos de juicio aportados al proceso y el texto de la noticia acusada demuestran que la forma en la que fue presentado el reportaje desconoció el principio de veracidad, en su componente, de proporcionar información exacta e inequívoca" (Sentencia T-200/18, 2018). En ese sentido, el alto tribunal concluyó que la vulneración de los derechos a la honra y al buen nombre se materializó cuando el afectado fue mostrado ante la sociedad como una persona borracha e infractora de la ley, tal argumento se recoge del siguiente fragmento del fallo:

La conducta objeto de reproche constitucional, también derivó en la violación de los derechos fundamentales al buen nombre y a la honra del actor, comoquiera que fue etiquetado por su comunidad como un "borracho" e infractor de la ley, pese a que, como fue demostrado con antelación, no existe plena certeza de que lo informado corresponde a la situación del accionante. (Sentencia, T-200/18, 2018)

Así las cosas, la Corte procedió a la elaboración de una relación de precedencia orientada a dar prevalencia a los principios honra y buen nombre, la cual se ilustra a continuación: P2 precede a Pl en el caso concreto, toda vez que el medio de comunicación desconoció el principio de veracidad en su componente de proporcionar información exacta e inequívoca.

\subsection{SU-274 de 2019}

La Sentencia SU-274/19 (2019), es el pronunciamiento de unificación jurisprudencial más reciente emitido por la Sala Plena de Corte Constitucional en lo que respecta a una colisión entre los principios libertad de expresión versus honra y buen nombre. Los elementos fácticos que se extraen del caso pueden sintetizarse de la siguiente 
manera: el señor Luis Ramos Botero quien ha desempeñado cargos públicos de gran importancia, tales como alcalde de una ciudad, gobernador de un departamento y senador de la república, ha sido investigado durante varios años por la Corte Suprema de Justicia por la comisión de algunos delitos relacionados con la vinculación con grupos paramilitares. El día 20 de enero del año 2018, Noticias Uno divulgó como hecho noticioso la existencia de un proyecto de sentencia donde se proponía un fallo condenatorio para el procesado. Ramos Botero consideró que la divulgación de esta noticia vulneraba sus derechos a la honra, al buen nombre y a la presunción de inocencia, por tal razón, solicitó al canal que rectificara la información en las mismas condiciones en las que fue emitida y la retirara de su canal de YouTube. El canal accedió parcialmente a lo solicitado y rectificó algunas afirmaciones hechas dentro de la noticia macro en donde se vinculaba al procesado con unos hechos particulares de conformación de grupos paramilitares, los cuales no eran objeto de debate en el proceso penal al cual correspondía el proyecto de fallo condenatorio. Pero en todo lo demás la noticia siguió intacta; por estas razones, Ramos Botero presentó una acción de tutela para buscar la salvaguarda de sus derechos fundamentales.

Una vez emitidas las decisiones de instancia, el expediente pasó a la Corte Constitucional para su eventual revisión, siendo seleccionado e incluso empleado para una decisión de unificación por parte de su Sala Plena. Si solo se extraen los elementos que son útiles para este trabajo, se puede afirmar que en el caso concreto hay dos problemas jurídicos palpables, los cuales se formulan de la siguiente manera:

1. ¿La divulgación a través de medios de comunicación de información judicial sobre una eventual condena aun cuando no hay sentencia definitiva vulnera los derechos a la honra y al buen nombre de terceros?

2. ¿Los periodistas pueden divulgar información con carácter de reserva suministrada por sus fuentes, o tal proceder afecta el derecho a la honra y al buen nombre de terceros?

En cuanto al problema jurídico número uno la alta corporación expresó lo siguiente:

El ejercicio adecuado de la libertad de información implica que la noticia difundida sea contrastada con fuentes y fundamentada en hechos reales, pues de lo contrario, se atentaría contra los derechos a la honra y al buen nombre. Visto esto, la Sala encuentra que Noticias Uno no vulneró los derechos a la honra y al buen nombre. (Sentenc

De este fragmento se puede extraer la relación de precedencia condicionada que se expone a continuación: Pl precede a P2 en el caso concreto, toda vez que la noticia difundida fue contrastada con fuentes y fundamentada en hechos reales.

Ahora bien, en lo que respecta al segundo problema jurídico, la Corte Constitucional (2019) hizo referencia a los esfuerzos del ordenamiento legal para evitar la 
divulgación de información que ostente la calidad de reservada, especialmente la relativa a los asuntos judiciales y administrativos. En este sentido, advierte que tales incumplimientos pueden traer consecuencias penales y disciplinarias, y puntualizó que:

Esta limitación no comprende —en principio—a los periodistas ni a los medios de comunicación, por lo que no podría ser entendida exactamente como una restricción para el ejercicio de la libertad de información, sino como una prohibición en cabeza de los funcionarios públicos que tienen a su cargo el conocimiento y la custodia de dichos asuntos. En otras palabras, las sanciones por la divulgación de información sujetan a reserva, conciernen únicamente a los servidores públicos que la revelaron, por lo que no pueden recaer sobre los medios de comunicación, salvo que estos hubieran cometido fraude o un delito para obtenerla. [...] A juicio de esta Corporación, Noticias Uno no tenía en este caso la obligación legal de mantener bajo reserva el proyecto de sentencia que le fue suministrado, pues tal deber recae sobre los funcionarios que tenían a su cargo la custodia del expediente del proceso penal. (Sentencia SU-274/19, 2019)

Así las cosas, para solucionar el problema jurídico número dos la Corte estableció la relación de precedencia que se enuncia a continuación: P1 precede a P2 en el caso concreto, toda vez que la obligación de mantener la reserva de la información se encontraba en cabeza de los funcionarios que tienen a su cargo la custodia de la misma, y no se comprobó que el medio de comunicación la hubiera obtenido a través de fraude o delito.

\section{CONCLUSIONES}

No cabe duda de que los principios libertad de expresión, honra y buen nombre gozan de un gran respaldo en el Derecho Internacional de los Derechos Humanos, en el derecho doméstico y en la jurisprudencia de la Corte Constitucional, y que además, estos son fieles protagonistas de colisiones derivadas de las actividades periodísticas, ya sea en Colombia o en cualquier Estado que reconozca y posibilite el ejercicio de tales garantías. Así mismo, resulta evidente que al momento de dirimir estas controversias no existen fórmulas mágicas que permitan una solución homogénea aplicable de manera estandarizada, ya que las respuestas de los operadores judiciales dependerán de las circunstancias específicas de cada caso concreto. Esto es así, para lograr optimizar los derechos y generar el menor grado de lesividad posible, cuestión que a su vez evita el aprovechamiento desproporcionado del carácter prevalente prima facie que tiene la libertad de expresión en su manifestación de libertad de información, y también, impide la censura excusada en la necesidad de una protección desmedida de los derechos a la honra y al buen nombre.

Aunado a lo anterior, vale decir que de acuerdo con la jurisprudencia constitucional analizada, los componentes de veracidad e imparcialidad son factores determinantes al momento de establecer relaciones de precedencia condicionada en las colisiones entre los principios libertad de expresión, honra y buen nombre 
por el ejercicio de actividades periodística, toda vez que la inclinación de la balanza hacia un lado u otro depende, por lo general, del esfuerzo que haya realizado el medio de comunicación por corroborar la información y del mayor o menor grado de imparcialidad con el que haya sido difundida.

Por último, en lo atinente a la ponderación, es importante mencionar que hasta el momento resulta ser la herramienta aplicable por excelencia cuando se presentan colisiones entre derechos fundamentales, pues a pesar de ser bastante cuestionada debido a su probable amplio margen de subjetividad, ayuda a la toma de decisiones basadas en argumentos convincentes que minimizan las posibilidades de privilegiar un derecho a través de la exclusión injustificada y arbitraria de otro.

\section{REFERENCIAS}

Alexy, R. (1993). Teoría de los derechos fundamentales. Centro de Estudios Constitucionales.

Asamblea Nacional Constituyente. (1991). Constitución Política de Colombia. http://www. secretariasenado.gov.co/senado/basedoc/constitucion_politica_1991.html

Bernal Pulido, C. (2006). La racionalidad de la ponderación. Revista española de derecho, 26(77), 51-75. https://dialnet.unirioja.es/servlet/articulo?codigo $=2233706$

Comisión Interamericana de Derechos Humanos, CIDH. (2009). Marco Jurídico Interamericano sobre el Derecho a la Libertad de Expresión. https://bit.ly/3mGEuOF

Corte Constitucional (1995, 13 de septiembre). Sentencia T-411/95 (Alejandro Martínez Caballero, M.P.). https://www.corteconstitucional.gov.co/relatoria/1995/t-41 1-95.htm\#: :text=T\%2D41 1\%2D95\%20 Corte\%20Constitucional\%20de\%20Colombia\&text $=$ El\%20criterio\%20con\%20que\%20 conoce,ha\%20anticipado\%20en\%20su\%20conocimiento.

Corte Constitucional (1995, 26 de septiembre). Sentencia T-425/95 (Eduardo Cifuentes Muñoz, M.P.). https://www.corteconstitucional.gov.co/relatoria/1995/T-425-95.htm

Corte Constitucional (1998, 5 de marzo). Sentencia T-066/98 (Eduardo Cifuentes Muñoz, M. P.). https:// www.corteconstitucional.gov.co/relatoria/1998/t-066-98.htm

Corte Constitucional (2000, 12 de diciembre). Sentencia SU-1723/00 (Alejandro Martínez Caballero, M. P.). https://www.corteconstitucional.gov.co/relatoria/2000/SU1723-00.htm

Corte Constitucional (2001, 14 de junio). Sentencia T-634/01 (Jaime Araujo Rentería, M.P.). https://www. corteconstitucional.gov.co/relatoria/2001/t-634-01.htm

Corte Constitucional (2009, 27 de marzo). Sentencia T-219/09 (Mauricio González Cuervo, M.P.). https:// www.corteconstitucional.gov.co/relatoria/2009/t-219-09.htm

Corte Constitucional (2011, 25 de mayo). Sentencia C-442/11 (Humberto Antonio Sierra Porto, M. P.).

Corte Constitucional (2011, 3 de febrero). Sentencia T-043/11 (Humberto Antonio Sierra Porto, M. P.).

Corte Constitucional (2015, 22 de mayo). Sentencia T-312/15 (Jorge Iván Palacio Palacio, M.P.). https:// www.corteconstitucional.gov.co/relatoria/2015/T-312 15.htm\#: :text=\%E2\%80\%9CSe\%20 garantiza\% 20 a $\% 20$ toda $\% 20$ persona, fundar\% 20 medios $\% 20$ masivos $\% 20$ de\% 20 comunicaci\%C3\%B3n.Etext=El\%20sistema\%20constitucional\%20consagra\%20as\%C3\%AD\%20 
simult\%C3\%A1 neamente\%20varios\%20derechos\%20y\%20libertades\%20fundamentales\%20 distintas.,-Principalmente\%2C\%20establece\%20la

Corte Constitucional (2015, 27 de noviembre). Sentencia T-731/15 (Myriam Ávila Roldán, M.P.). https:// www.corteconstitucional.gov.co/relatoria/2015/T-731-15.htm

Corte Constitucional (2018, 25 de mayo). Sentencia T-200/18 (Alejandro Linares Cantillo, M. P.). https:// www.corteconstitucional.gov.co/relatoria/2018/T-200-18.htm

Corte Constitucional (2018, 6 de abril). Sentencia T-117/18 (Cristina Pardo Schlesinger, M. P.). https:// www.corteconstitucional.gov.co/relatoria/2018/T-117-18.htm

Corte Constitucional (2019, 19 de junio). Sentencia SU-274/19 (José Fernando Reyes Cuartas, M. P.). https://www.corteconstitucional.gov.co/relatoria/2019/SU274-19.htm

Diego, L. (2006). El derecho de los jueces (2. ${ }^{\text {, }}$, ed.). Legis.

García Amado, J. (2016). Un debate sobre la ponderación. Palestra editores.

Naciones Unidas. (1948). Declaración Universal de los Derechos Humanos. https://www.un.org/es/universaldeclaration-human-rights/

Naciones Unidas. (1966). Pacto Internacional de Derechos Civiles y Políticos. https://www.ohchr.org/sp/ professionalinterest/pages/ccpr.aspx

Naciones Unidas. (1989). Convención sobre los Derechos del Niño. https://www.ohchr.org/SP/ ProfessionalInterest/Pages/CRC.aspx

Naciones Unidas. (1990). Convención Internacional sobre la Protección de los Derechos de todos los Trabajadores Migratorios $y$ de sus Familiares. https://www.ohchr.org/sp/professionalinterest/pages/cmw.aspx

Naciones Unidas. (2006). Convención Internacional sobre los Derechos de las Personas con Discapacidad. https:// www.un.org/esa/socdev/enable/documents/tccconvs.pdf

Nikken, P. (s. f.) La declaración universal y la declaración americana. La formación del moderno derecho internacional de los derechos humanos. https://www.corteidh.or.cr/tablas/R06857-3.pdf

Organización de Estados Americanos, OEA. (1948). Declaración Americana de los Derechos y Deberes del Hombre. https://bit.ly/3249lNT

Organización de Estados Americanos, OEA. (1969). Convención Americana sobre Derechos Humanos. https:// bit.ly/3wPIWBh

Organización de Estados Americanos, OEA. (2000). Declaración de Principios sobre Libertad de Expresión. https://www.cidh.oas.org/basicos/declaracion.htm

Organización de Estados Americanos, OEA. (2001). Carta Democrática Interamericana. https://www.oas. org/charter/docs_es/resolucion1_es.htm 